\title{
TỶ LỆ TRẺ SINH NHẸ CÂN TẠI TUYẾN BỆNH VIỆN CỦA TỈNH XIÊNG KHOẢNG, CộNG HOÀ NHÂN DÂN LÀO NĂM 2020 VÀ MộT SỐ YẾU TỐ LIÊN QUAN
}

\author{
Keobouavanh Phongphakdy' và Đinh Thị Phương Hoà ${ }^{2}$ \\ 1. Bệnh viện tỉnh Xiêng Khoảng, Cộng hoà nhân dân Lào \\ 2. Viện Nghiên cứu sức khoẻ trẻ em Bệnh viện Nhi Trung ương
}

\begin{abstract}
TÓM TẮT
Cân nặng khi sinh là một chỉ số quan trọng phản ảnh sức khoẻ và dinh dưỡng của bà mẹ và thai nhi. Trẻ sinh nhẹ cân (SNC) có nhiều nguy cơ tử vong, suy dinh dướng, chỉ số IQ thấp ở trẻ em và tăng nguy cơ mắc một số bệnh mạn tính khi trưởng thành. Giảm tỷ lệ SNC là một ưu tiên của các can thiệp cộng đồng, vì thế nghiên cứu này được tiến hành nhằm mô tả thực trạng trẻ SNC và một số yếu tố liên quan tại các bệnh viện thuộc tỉnh Xiêng Khoảng, Cộng hoà nhân dân Lào trong năm 2020. Kết quả thu được sẽ là cơ sở để có can thiệp phù hợp giảm tỷ lệ SNC tại địa bàn nghiên cứu.

Sử dụng phương pháp mô tả cắt ngang với đối tượng là 899 bà mẹ và 925 trẻ sơ sinh tại bệnh viện tỉnh và 6 bệnh viện huyện. Kết quả cho thấy tỷ lệ trẻ SNC là 8,6\% (tuyến tỉnh: 8,2\%, tuyến huyện: 9,4\%). Trẻ sinh non; Trẻ gái; Con so và trẻ sinh đôi có tỷ lệ SNC cao hơn (theo thứ tự là: 18,$9 ; 9,6 ; 11,6$ và 28,9\%). Một số yếu tố từ mẹ liên quan có ý nghĩa thống kê đến SNC bao gồm: nguy cơ của các bà mẹ có $B M I<18,5$; không khám thai cao hơn 2,4 và 1,7 . Các bà mẹ tăng cân ít (<5 kg) hoặc quá nhiều (>12 kg) trong thai kỳ có nguy cơ cao hơn 1,7 và 2,1 lần. Bà mẹ có học vấn đại học/sau đại học nguy cơ SNC chỉ bằng 0,6 lần bà mẹ có trình độ trung học.

Can thiệp giảm tỷ lệ sinh nhẹ cân tại Xiêng khoảng cân tập trung chăm sóc tốt bà mẹ trong thời gian mang thai, đặc biệt chú trọng tư vấn về khám thai và dinh dướng; Ưu tiên các bà mẹ có BMI thấp, có con lân đầu và sinh đôi.
\end{abstract}

Từ khoá: Trẻ sinh nhẹ cân, Xiêng Khoảng, Cộng hoà nhân dân Lào.

\section{ABSTRACT \\ PREVALENCE OF LOW BIRTHWEIGHT BABIES AT HOSPITAL LEVELS IN XIENG KHOANG PROVINCE, LAO PEOPLE'S DEMOCRATIC REPUBLIC IN 2020 AND SOME RELATED FACTORS}

Birth weight is an important indicator of maternal and fetal health and nutrition. Low birthweight (LBW) newborns have a higher risk of dying, more likely to suffer from stunted growth and lower IQ in children and increasing the risk of adult- onset chronic conditions. Reducing LBW has long been recognized as a public health priority, therefore, this study was carried out to describe the LBW prevalence and some related factors in hospitals in Xieng Khoang province, Lao People's Democratic

Nhận bài: 10-1-2021; Chấp nhận: 10-2-2021

Người chịu trách nhiệm chính: Đinh Thị Phương Hòa

Địachi:phuonghoa55@yahoo.com 
Republic in 2020. The result will be used for proper interventions to reduce LBW at the study area. A cross-sectional study conducted with among 899 mothers and 925 newborns in a provincial hospital and 6 district hospitals. The results showed that LBW prevalence was $8.6 \%$ ( $8.2 \%$ in province and $9,4 \%$ in district hospitals). Premature; girl; first-born newborns and twin had a higher rate of $\operatorname{LBW}(18,9 ; 9,6$; 11,6 và $28,9 \%$, respectively). Some maternal factors significant associated with LBW baby including $\mathrm{BMI}<18,5$; no antenatal care visit (ANC) with OR were 2,4 and 1,7. Mothers with less weight gain $(<5 \mathrm{~kg})$ or much $(>12 \mathrm{~kg})$ during pregnancy had higher with 1,7 and 2,1 times. Educated mothers at university level or more had less risk for LBW with only 0.6 times to compare with those at secondary school. Interventions to reduce LBW rate in Xieng Khoang province rate need to improve care of mothers during pregnancy, especially to consult for ANC visit and proper nutrition. Mothers with low $B M I$, first and twin pregnancy need to be prioritized.

Key words: Low birthweight (LBW); Xieng Khoang; Lao People's Democratic Republic.

\section{1. ĐẶT VẤN ĐÊ}

Trẻ đẻ nhẹ cân (cân nặng khi đẻ <2500g) vẫn còn là một thách thức lớn đối với sức khoẻ cộng đồng khi hàng năm trên thế giới có tới khoảng 20,5 triệu trẻ sinh ra nhẹ cân, chiếm gần $15 \%$ trong tổng số trẻ được sinh ra [1]. Trẻ đẻ nhẹ cân (TĐNC) là một trong những nguyên nhân chính gây tử vong sơ sinh và trẻ dưới 5 tuổi [2]. Những trẻ sống được có nguy cơ cao mắc các bệnh nhiễm khuẩn, tổn thương thần kinh, rối loạn phát triển ngôn ngữ và có chỉ số thông minh thấp [3]. Trẻ đẻ nhẹ cân cũng có nhiều nguy cơ mắc các bệnh mạn tính như béo phì, đái tháo đường khi trưởng thành. Trẻ đẻ nhẹ cân do sinh non tháng còn có thêm các nguy cơ do các cơ quan chưa trưởng thành như xuất huyết não, suy hô hấp, nhiễm khuẩn, mù và rối loạn chức năng dạ dày, ruột [3]. Can thiệp giảm TĐNC sẽ góp phần quyết định giảm tử vong trẻ em, nâng cao chất lượng dân số và thúc đẩy tiến trình đạt mục tiêu hậu thiên niên kỷ về sức khoẻ vào năm 2030 [4].

Nước cộng hoà nhân dân Lào (CHND Lào) là một trong những nước nghèo ở khu vực châu Á. Theo ước tính của WHO và UNICEF, tỷ lệ TĐNC tại Lào vào khoảng $11,6-22,6 \%$, cao hơn so với số báo cáo của Bộ Y tế Lào [5]. Nhằm xác tỷ lệ
TĐNC và một yếu tố liên quan để có kế hoạch can thiệp, nghiên cứu này được thực hiện với 2 mục tiêu sau:

1. Mô tả thực trạng trẻ đẻ nhẹ cân tại các bệnh viện tỉnh và huyện tại tỉnh Xiêng Khoảng.

2. Xác định một số yếu tố liên quan đến trẻ đẻ nhẹ cân năm 2020.

\section{2. ĐốITƯợNG VÀ PHƯơNG PHÁP NGHIÊN CỨU}

Nghiên cứu được tiến hành tại các bệnh viện tỉnh và 6 bệnh viện huyện thuộc tỉnh Xiêng Khoảng, một tỉnh giáp với tỉnh Nghệ An của Việt Nam.

2.1. Đối tượng nghiên cứu: là tất cả các bà mẹ và trẻ mới sinh tại các bệnh viện trên trong 3 tháng năm 2020 (từ 1/3 - 30/5/2020) bao gồm 899 bà mẹ và 925 trẻ sơ sinh.

2.2. Phương pháp nghiên cứu: Sử dụng phương pháp mô tả cắt ngang. Thu thập số liệu bằng cách dùng bộ câu hỏi có cấu trúc phỏng vấn trực tiếp bà mẹ trước khi ra viện.

Số liệu được phân tích bằng phần mềm SPSS 22.0. Kết quả được trình bày theo tỷ lệ, các giá trị trung bình, độ lệch chuẩn. So sánh, tìm mối liên quan bằng tỷ suất chênh ( $\mathrm{OR}$, khoảng tin cậy) và giá trị p. 
TẠP CHÍ NHI KHOA 2021, 14, 1

\section{KẾT QUẢ NGHIÊN CỨU}

Bảng 1. Thông tin chung về đối tượng nghiên cứu

\begin{tabular}{|c|c|c|c|c|c|}
\hline \multicolumn{3}{|c|}{ Mẹ (n=899) } & \multicolumn{3}{|c|}{ Con $(n=925)$} \\
\hline Các chỉ số & $\mathbf{n}$ & $\%$ & Các chỉ số & $\mathbf{n}$ & $\%$ \\
\hline $\begin{array}{l}\text { Tuổi mẹ: } \\
\qquad \begin{array}{l}-\leq 20 \\
-21 \text { - } 34 \\
-\geq 35\end{array}\end{array}$ & $\begin{array}{c}243 \\
604 \\
52\end{array}$ & $\begin{array}{c}27,0 \\
67,2 \\
5,8\end{array}$ & $\begin{array}{l}\text { Tuổi thai: } \\
\qquad \begin{array}{l}\text { - } 37 \text { tuần } \\
\text { - } 37 \text { - } 41 \text { tuần } \\
\text { - } \geq 42 \text { tuần }\end{array}\end{array}$ & $\begin{array}{c}74 \\
837 \\
14\end{array}$ & $\begin{array}{c}8,0 \\
90,5 \\
1,5\end{array}$ \\
\hline $\begin{array}{l}\text { BMI: } \\
\quad-<18,5 \\
-18,5-22,9 \\
-\geq 23\end{array}$ & $\begin{array}{l}81 \\
598 \\
220\end{array}$ & $\begin{array}{c}9,0 \\
66,5 \\
24,5\end{array}$ & $\begin{array}{l}\text { Thứ tự sinh: } \\
\text { - Con so } \\
\text { - Con rạ }\end{array}$ & $\begin{array}{l}276 \\
649\end{array}$ & $\begin{array}{l}29,8 \\
70,2\end{array}$ \\
\hline $\begin{array}{l}\text { Nghềnghiệp: } \\
\text { - Nông dân } \\
\text { - Văn phòng } \\
\text { - Công nhân, tự do }\end{array}$ & $\begin{array}{c}728 \\
108 \\
63\end{array}$ & $\begin{array}{c}81 \\
12,0 \\
7,0\end{array}$ & $\begin{array}{l}\text { Giới: } \\
\text { - Trai } \\
\text { - Gái }\end{array}$ & $\begin{array}{l}520 \\
405\end{array}$ & $\begin{array}{l}56,2 \\
43,8\end{array}$ \\
\hline $\begin{array}{l}\text { Học vấn: } \\
\text { - Mù chữ } \\
\text { - Tiểu học } \\
\text { - Trung học } \\
\text { - } \geq \text { Đại học }\end{array}$ & $\begin{array}{l}51 \\
221 \\
512 \\
115\end{array}$ & $\begin{array}{l}5,7 \\
24,6 \\
57,0 \\
12,8\end{array}$ & $\begin{array}{l}\text { Cách sinh: } \\
\text { - Sinh thường } \\
\text { - Mổ } \\
\text { - Sinh một } \\
\text { - Sinh đôi }\end{array}$ & $\begin{array}{c}743 \\
182 \\
873 \\
52\end{array}$ & $\begin{array}{c}80,3 \\
19,7 \\
94,4 \\
5,6\end{array}$ \\
\hline $\begin{array}{l}\text { Kinh tế gia đình: } \\
\text { - Nghèo } \\
\text { - Trung bình } \\
\text { - Giàu }\end{array}$ & $\begin{array}{l}328 \\
407 \\
164\end{array}$ & $\begin{array}{l}36,5 \\
45,3 \\
18,2\end{array}$ & $\begin{array}{l}\text { Tinh trạng trẻ sau sinh: } \\
\text { - Bình thường } \\
\text { - Có dị tật }\end{array}$ & $\begin{array}{c}887 \\
38\end{array}$ & $\begin{array}{c}95,9 \\
4,1\end{array}$ \\
\hline
\end{tabular}

Số liệu ở bảng 1 là các thông tin về 899 bà mẹ và 925 trẻ sơ sinh trong nghiên cứu. Phần lớn các bà mẹ ở độ tuổi từ 21-34 (67,2\%); vẫn có 5,8\% số bà mẹ $\geq 35$ tuổi. Có $9,0 \%$ số bà mẹ bị thiếu năng lượng trường diễn $(\mathrm{BMI}<18,5)$ và $24,5 \%$ số bà mẹ thừa cân/béo phì (BMI $\geq 23$ ). Có $81,0 \%$ số bà me trong nghiên cứu là nông dân. Tỷ lệ bà mẹ đã tốt nghiệp trung học $(57,0 \%)$; đại học/sau đại học là $12,8 \%$; Vẫn còn $5,7 \%$ số bà me mù chũ. Có tới $36,5 \%$ số bà mẹ sống trong gia đình nghèo và 18,2\% là hộ giàu.

Phần lớn trẻ $(90,5 \%)$ sinh đủ tháng. Số trẻ sinh non tháng là $8,0 \%$ và sinh già tháng $1,5 \%$. Có $29,8 \%$ là con đầu. Số là trẻ trai nhiều hơn trẻ gái $(56,2 \%$ so với $43,8 \%)$. Tỷ lệ trẻ sinh mổ là $19,7 \%$. Có 4,1\% trẻ bị dị tật bẩm sinh. 


\subsection{Hiện trạng về trẻ sinh nhẹ cân}

\subsubsection{Tỷ lệ trẻ sinh nhẹ cân}

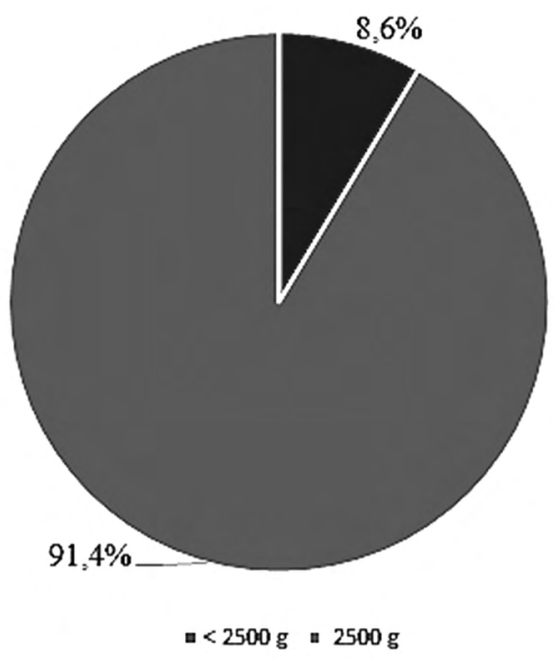

Hình 1. Tỷ lệ trẻ sinh nhẹ cân

Trẻ sinh nặng cân nhất là 4100 gram và nhẹ nhất 1600 gram. Cân nặng trung bình của các trẻ là $2825 \pm 464$ gram.

Số trẻ sinh nhẹ cân (< 2500 gram) trong nghiên cứu là 80 , chiếm tỷ lệ 8,6\%.

\subsubsection{Phân bố trẻ sinh nhẹ cân theo tuyến bệnh viện}

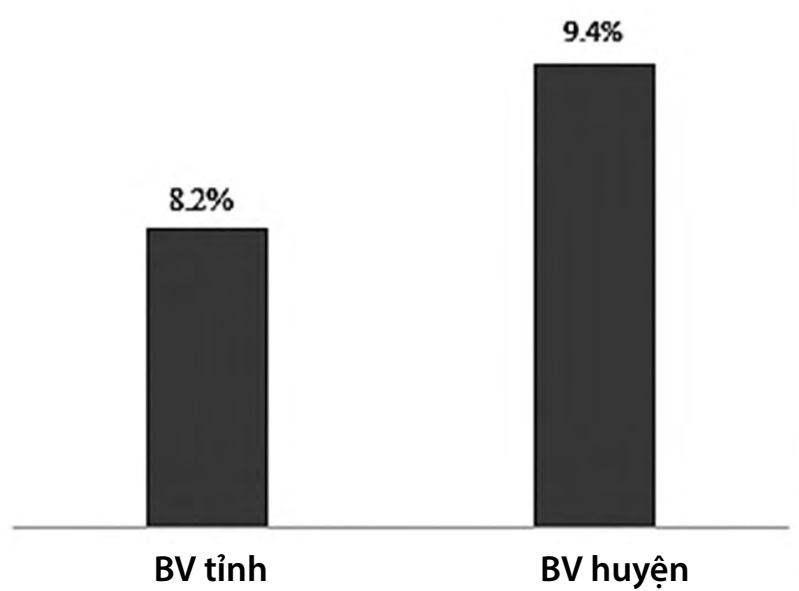

Biểu đồ 2. Tỷ lệ sơ sinh nhẹ ở bệnh viện tỉnh và bệnh viện huyện

Tỷ lệ sơ sinh nhẹ cân tại bệnh viện tỉnh 8,2\%, các bệnh viện huyện 9,4\%. 
TẠP CHÍ NHI KHOA 2021, 14, 1

\subsubsection{Tỷ lệ trẻ sinh nhẹ cân theo các đặc điểm của trẻ}

Bảng 2. Tỷ lệ sơ sinh nhẹ cân theo tuổi thai, giới, thứ tự sinh tính (n=925)

\begin{tabular}{|c|c|c|c|}
\hline Giới & Tần số & $\%$ & \multirow{7}{*}{$\begin{array}{l}\text { Tỷ lệ sinh nhẹ cân ở trẻ gái }(7,9 \%) \text { cao hơn so với } \\
\text { trẻ trai }(9,6 \%) ; \text { tuy nhiên sự khác biệt không có ý } \\
\text { nghĩa thống kê (p>0,05). } \\
\text { Tỷ lệ đẻ nhẹ cân ở trẻ đẻ non }(18,9 \%) \text { cao gần gấp } \\
2,5 \text { lần với nhóm còn lại }(7,9 \%) \text { và ở những trè là } \\
\text { con so là } 11,6 \% \text { cao hơn so với con rạ } 7,4 \% \text {. Trẻ } \\
\text { sinh đôi có tỷ lệ đẻ nhẹ cân cao tới } 28,9 \% \text {. } \\
\text { Sự khác biết có ý nghĩa thống kê với p }<0,05\end{array}$} \\
\hline Trai $(n=520)$ & 41 & 7,9 & \\
\hline Gái (n=405) & 39 & 9,6 & \\
\hline$<37(n=74)$ & 14 & 18,9 & \\
\hline$\geq 37(n=851)$ & 66 & 7,9 & \\
\hline Con so $(n=276)$ & 32 & 11,6 & \\
\hline Con rạ (649) & 48 & 7,4 & \\
\hline Sinh đôi (n=52) & 15 & 28,9 & \\
\hline
\end{tabular}

\subsection{Một số yếu tố liên quan từ mẹ đến trẻ đẻ nhẹ cân}

Bảng 3. Liên quan giữa yếu tố cá nhân của mẹ và sinh con nhẹ cân

\begin{tabular}{|c|c|c|c|c|c|}
\hline \multicolumn{2}{|l|}{ Đặc điểm } & $\begin{array}{l}\text { Có } \\
\text { (n) }\end{array}$ & $\begin{array}{c}\text { Không } \\
\text { (n) }\end{array}$ & $\begin{array}{c}\text { OR } \\
\text { (CI 95\%) }\end{array}$ & $\mathbf{P}$ \\
\hline \multirow{4}{*}{ Nhóm tuổi } & $\leq 20$ & 20 & 223 & $0,8(0,6-1,7)$ & $>0,05$ \\
\hline & $21-27$ & 36 & 336 & 1 & \\
\hline & $28-34$ & 18 & 214 & $0,8(0,4-1,3)$ & $>0,05$ \\
\hline & $\geq 35$ & 06 & 46 & $1,2(0,4-2,8)$ & $>0,05$ \\
\hline \multirow{3}{*}{$\begin{array}{l}\text { Chỉ số khối cơ thể } \\
\text { (BMI) trước khi } \\
\text { mang thai }\end{array}$} & $<18,5$ & 12 & 69 & $2,4(1,1-5,0)$ & $<0,05$ \\
\hline & $18,5-22,9$ & 46 & 552 & 1 & \\
\hline & $\geq 23$ & 22 & 198 & $1,4(0,8-2,4)$ & $>0,05$ \\
\hline \multirow{3}{*}{ Nghề nghiệp } & Nông dân & 67 & 661 & 1 & \\
\hline & Văn phòng & 6 & 102 & $0,6(0,2-1,1)$ & $>0,05$ \\
\hline & Công nhân, tự do & 7 & 56 & $1,3(0,9-4,4)$ & $>0,05$ \\
\hline \multirow{4}{*}{ Trình độ học vấn } & Mù chũ & 3 & 48 & $0,3(0,2-1,5)$ & $>0,05$ \\
\hline & Tiểu học & 17 & 204 & $1,5(0,6-2,2)$ & $>0,05$ \\
\hline & Trung học & 24 & 488 & 1 & \\
\hline & Đại học/sau đại học & 36 & 79 & $0,6(0,2-0,8)$ & $<0,01$ \\
\hline
\end{tabular}

Các bà mẹ có $B M I<18,5 \mathrm{~kg} / \mathrm{m}^{2}$ tăng nguy cơ sinh con nhẹ cân 2,4 lần so với bà mẹ có chỉ số $B M I$ bình thường. Bà mẹ có trình độ đại học và sau đại học có nguy có sinh con nhẹ cân chỉ bằng 0,6 lần bà mẹ có trình độ trung học. Hai mối liên quan này có ý nghĩa thông kê. Không thấy mối liên quan có ý nghĩa thống kê giữa yếu tố tuổi, nghề nghiệp của mẹ với sinh con nhẹ cân. 
Bảng 4. Liên quan giữa chăm sóc trong thai kỳ và sinh nhẹ cân ( $n=899)$

\begin{tabular}{|c|c|c|c|c|c|}
\hline \multicolumn{2}{|l|}{ Đặc điểm } & $\begin{array}{l}\text { Có } \\
\text { (n) }\end{array}$ & $\begin{array}{c}\text { Không } \\
\text { (n) }\end{array}$ & $\begin{array}{c}\text { OR } \\
\text { (Cl 95\%) }\end{array}$ & $\mathbf{p}$ \\
\hline \multirow{3}{*}{ Số lần khám thai } & 0 & 6 & 40 & $1,7(1,6-13,2)$ & $<0,05$ \\
\hline & $1-3$ & 41 & 402 & $1,2(1,0-2,6)$ & $>0,05$ \\
\hline & $\geq 4$ & 33 & 377 & 1 & \\
\hline \multirow{2}{*}{ Uống viên sắt } & Có & 51 & 517 & 1 & \multirow{2}{*}{$>0,05$} \\
\hline & Không & 29 & 302 & $1.0(0,5-1,2)$ & \\
\hline \multirow{2}{*}{ Tiêm phòng uốn ván } & Có & 47 & 509 & $0,9(0,3-5,8)$ & \multirow{2}{*}{$>0,05$} \\
\hline & Không & 33 & 310 & 1 & \\
\hline \multirow{4}{*}{$\begin{array}{l}\text { Tăng cân trong thời kỳ } \\
\text { mang thai }\end{array}$} & $\leq 5 \mathrm{~kg}$ & 17 & 40 & $8,3(2,3-19,7)$ & $<0,05$ \\
\hline & $5,1-10 \mathrm{~kg}$ & 41 & 435 & $1,8(1,1-6,7)$ & $<0,05$ \\
\hline & $10,1-12 \mathrm{~kg}$ & 16 & 313 & 1 & \\
\hline & $>12 \mathrm{~kg}$ & 06 & 57 & $2,1(1,2-8,9)$ & $<0,05$ \\
\hline
\end{tabular}

Hai yếu tố về chăm sóc trong thời gian mang thai liên quan có ý nghĩa thống kê là khám thai và tăng cân. Các bà mẹ không khám thai tăng nguy cơ sinh con nhẹ cân cao hơn 1,7 lần. Các bà mẹ tăng cân ít trong thai kỳ $(<5 \mathrm{~kg})$ và tăng cân nhiều (>12 kg) có nguy cơ sinh con nhẹ cân cao hơn 8,3 và 2,1 lần. Không tìm thấy mối liên quan có ý nghĩa thống kê về việc uống viên sắt, tiêm phòng uốn ván với sinh con nhẹ cân.

\section{BÀN LUÂN}

Tỷ lệ trẻ SNC trong nghiên cứu của chúng tôi là 8,6\%, cao hơn số báo cáo thống kê năm 2018 của tỉnh Xiêng Khoảng là 7,0\% [6]. Điều này có thể giải thích được vì số liệu của chúng tôi là thu thập trong bệnh viện, có điều kiện cân tất cả các trẻ đến sinh tại bệnh viện còn số báo cáo có thể tính trên mẫu số bao gồm cả những trẻ không được cân nên tỷ lệ sẽ thấp hơn. Kết qua của chúng tôi so với các nghiên cứu từ những năm 2004-2013 tại Bệnh viện Bà mẹ và Trẻ em Lào (với tỷ lệ dao động từ 9,5\%-12,0\%) cho thấy tỷ lệ sinh nhẹ cân tại Lào tuy có cải thiện nhưng tốc độ còn chậm [7] và cao hơn số liệu chung của quốc gia và các nước xung quanh. Tỷ lệ trẻ nhẹ cân tại bệnh viện tỉnh 8,2\%, thấp hơn có ý nghĩa thống kê so với ở các bệnh viện huyện 9,4\%. Sự khác biệt này phản ánh tình trạng kinh tế, xã hội và chăm sóc bà mẹ, trẻ em tốt hơn ở thành phố và có thể là ở những phụ nữ không ở thành phố nhưng có điều kiện đến bệnh viện tỉnh sinh con.

Tỷ lệ trẻ sinh nhẹ cân do non tháng chiếm $18,9 \%$, cao hơn gấp 2 lần so với trẻ đủ tháng $(7,9 \%)$. Sinh trước 37 tuần thai là nguyên nhân chính dẫn đến không đạt được cân nặng bình thường vì 3 tháng cuối của thời kỳ mang thai là giai đoạn phát triển cân nặng của trẻ. Cần có những can thiệp dự phòng đẻ non tại Lào vì cũng như tình trạng ở một số nước trên thế giới, tỷ lệ đẻ non đang có xu hướng tăng tại Lào [7].

Trẻ gái có tỷ lệ sinh nhẹ cân $(9,6 \%)$ cao hơn trẻ trai (7,9\%) nhưng sự khác biệt không có ý nghĩa thống kê. Cân nặng khi sinh của trẻ gái nhẹ hơn trẻ trai có thể cũng là một nguyên nhân dẫn đến tỷ lệ trẻ SNC cao hơn ở trẻ gái. Tỷ lệ trẻ sinh nhẹ cân ở những trẻ là con so là $11,6 \%$ cao hơn có ý nghĩa so với con rạ (7,4\%). Giải thích hợp lý cho vấn đề này có thể là các bà mẹ có con lần đầu chưa có kinh nghiệm chăm sóc thai nghén tốt. Chức năng của tử cung ở lần mang thai đầu có thể chưa phải là tối ưu trong việc cung cấp dinh dưỡng cho thai nhi. Trẻ sinh đôi có tỷ lệ nhẹ cân 
cao nhất cũng là điều dễ hiểu khi nguồn dinh dưỡng từ mẹ cung cấp cho sự phát triển của thai phải chia sẻ cho 2 bào thai $[8,9]$.

Về một số yếu tố từ phía mẹ liên quan với trẻ sinh nhẹ cân, kết quả của chúng tôi cũng giống như một số nghiên cứu khác cho thấy trình độ học vấn thấp, không đi khám thai và tăng cân ít hoặc quá mức trong thời gian mang thai là những yếu tố tăng nguy cơ sinh con nhẹ cân [10]. Nghiên cứu của chúng tôi không tìm thấy một số yếu tố liên quan như tuổi mẹ, kinh tế gia đình, lao động nặng.v.v. Lý do chính có thể là cỡ mẫu không đủ lớn để phát hiện sự khác biệt. Đây cũng là hạn chế cần được khắc phục cho các nghiên cứu sau với thời gian dài hơn.

\section{KẾT LUẬN}

Tỷ lệ sinh con nhẹ cân ở địa bàn nghiên cứu còn ở mức cao so với toàn quốc. Cần phối hợp một số can thiệp giảm tỷ lệ trẻ nhẹ như khuyến khích phụ nữ đi khám thai đầy đủ, hướng dẫn họ biết chăm sóc thai, dinh dưỡng hợp lý. Cần đặc biệt chú ý hơn với các bà mẹ có con lần đầu và đa thai.

\section{TÀI LIỆU THAM KHẢO}

1. WHO - UNICEF 2019. Low Birthweight Estimates. Levels and Trends 2000-2015.

2. Badshah S, Mason L, McKelvie K, Payne R, Lisboa PJ. Risk factors for low birthweight in the public-hospitals at Peshawar, NWFP-Pakistan. BMC Pub Health 2008;8:197.

3. Zerbeto $A B$, Cortelo FM, Élio Filho BC. Association between gestational age and birth weight on the language development of Brazilian children: a systematic review. J de Pediatr 2015;91(4): 326-32.
4. You $D$, Hug $L$, Ejdemyr $S$, Idele $P$, Hogan $D$, Mathers $C$, et al. Global, regional, and national levels and trends in under- 5 mortality between 1990 and 2015, with scenario-based projections to 2030: a systematic analysis by the UN Inter - agency Group for Child Mortality Estimation. Lancet 2015; 386 (10010): 2275-86.

5. Lao P. Lao Social Indicator Survey (LSIS) 2011-2012 (Multiple indicator cluster survey/ demographics and health). Ministry of Health and Lao Statistics Bureau. 2010.

6. Sở Y tế tỉnh Xiêng Khoảng. Cộng hoà nhân dân Lào (2018). Số liệu thống kê y tế năm 2018.

7. Olsen SJ, Vetsaphong $P$, Vonglokham $P$, Mirza S, Khanthamaly V, Chanthalangsy T, et al. A retrospective review of birth outcomes at the Mother and Child Health Hospital in Lao People's Democratic Republic, 2004-2013. BMC Pregnancy and Childbirth. 2016;16(1): 379.

\section{Viengsakhone L, Yoshida Y, Harun - Or} - Rashid M, Sakamoto J. Factors affecting low birth weight at four central hospitals in Vientiane, Lao PDR. Nagoya J Med Sci. 2010; 72(1-2): 51-8.

9. Siza J. Risk factors associated with low birth weight of neonates among pregnant women attending a referral hospital in northern Tanzania. Tanzania journal of health research. 2008; 10(1): 1-8.

10. Lê Thị Phương Nhi. Nghiên cứu các yếu tố liên quan đến trẻ sơ sinh dưới 2500 gram tại huyện Phú Vang tỉnh Thừa Thiên Huế, Luận văn Thạc sĩ Y học, Đại học Y Dược Huế. 2009. 